D01: 10.12957/demetra.2016.20765

\title{
Mulheres em revista: representação corporal no imaginário social
}

Women in review: body representation in the social imaginary

Mariana Fernandes Costa

Jorge Coelho Soares ${ }^{2}$

1 Universidade do Estado do Rio de Janeiro, Instituto de Nutrição, Núcleo de Estudos sobre Cultura e Alimentação. Rio de Janeiro-RJ, Brasil.

${ }^{2}$ Universidade do Estado do Rio de Janeiro, Instituto de Psicologia, Programa de Pós-graduação em Psicologia Social. Rio de Janeiro-RJ, Brasil.

Essa pesquisa é resultado da dissertação de mestrado do Programa de Pós-graduação em Psicologia Social da Universidade do Estado do Rio de Janeiro, e foi financiada pelo CNPq.

Correspondência / Correspondence

Mariana Fernandes Costa

E-mail:marifcosta@gmail.com

\section{Resumo}

O objetivo foi analisar anúncios de alimentos e bebidas que contêm a figura corporal feminina veiculados nas revistas Seleções do Reader's Digest, no período de 1944-1948, e Claudia, de 2004-2008. O foco foi dado à análise semiótica dos anúncios para compreender o imaginário social da figura feminina em dois momentos. Foram identificados 82 anúncios de alimentos e bebidas, sendo 33 de Seleções e 49 de Claudia. A representação corporal da mulher foi organizada em duas categorias: imagem multifuncional e percepção corporal. No imaginário dos anúncios de Seleções transitam dois tipos de mulher: "mulher tradicional" - dona de casa (37,5\%), esposa (20,83\%); e "mulher moderna" - alegre $(37,5 \%)$, sensual (20\%) - que representam apenas um modelo de mulher: a "rainha do lar". Esses anúncios falam de relacionamentos, filhos e como agradar ao marido através da comida. Na revista Claudia, os mesmos papéis são executados, entretanto, constatamos um "avanço" no perfil mulher $(35,21 \%)$ ao longo das décadas: uma mulher que aparece inserida no mercado de trabalho $(9,86 \%)$, alegre $(26,04 \%)$, de corpo mais saudável $(22,92 \%)$ e belo $(21,87 \%)$, com um padrão de estética e beleza exposto e/ou imposto pela sociedade. Além disso, observou-se um aumento da imagem de mãe $(23,94 \%)$ nos anúncios, retratando a influência da mulher no consumo infantil. Portanto, podemos chamar a mulher dos dias atuais de "mulher hipermoderna", que além de exercer os papéis sociais de mãe-esposa-dona de casa-mulher-profissional, passou a um estágio superior de modernização.

Palavras-chave: Corpo humano. Anúncios, alimentos e bebidas. Identidade de gênero. 


\section{Abstract}

The aim of this study was to analyze food and beverage ads containing the female body figure (fragmented or whole) reported by Seleções (Reader's Digest) between 1944 and 1948 and Claudia magazine between 2004 and 2008. magazine advertisements were analyzed semiotically in order to shed light on the social imaginary of the female figure at two moments. We identified 82 food and beverage ads, 33 ads in the sample of Seleções and 49 ads in the sample of Claudia. The representation of women's body in the social imaginary was organized into two categories: multifunctional image and body perception. The ads in Seleções depict two types of women: "traditional woman" - housewife (37.5\%), wife (20.83\%); and "modern woman" - happy (37.5\%), sensual (20\%) - representing only one type of woman: "queen of the home". The ads address relationships, children and how women can please their husbands by means of food. In Claudia magazine, women roles were the same. However, we found an "advancement" in women's profile (35.21\%) over the decades: woman appear as active in the labor market (9.86\%), happy (26.04\%), with a healthier body (22.92\%) and a more beautiful body (21.87\%), as evidence of a beauty standard exposed and/ or imposed by society. In addition, there was an increase in the mother's image (23.94\%) in ads depicting the influence of women on children's consumption. Therefore, we call today's women "hypermodern women", who not only play social roles (motherwife-housewife-woman-professional) but have also moved on to a higher stage of modernization.

Key words: Human body. Advertisements, food and beverages. Gender identify.

\section{Introdução}

Diferentes áreas de conhecimento que estudam a alimentação, como a Psicologia, a Antropologia, a Sociologia e a Ciência da Nutrição, mostram em suas produções literárias os inúmeros conflitos, dilemas e paradoxos que cercam o tema e a sua relação com o corpo, a saúde e a boa forma. As várias abordagens e aspectos do consumo de alimentos e bebidas têm despertado interesse cada vez maior dos consumidores, das indústrias de alimentos, de políticas governamentais e da mídia em geral.

O corpo e assuntos relacionados a ele são objeto de estudo desde a Antiguidade até os dias atuais, representando um assunto de destaque em todos os momentos históricos, relacionado aos interesses e às necessidades da época. O corpo é um terreno de significados simbólicos, no qual as 
práticas e representações relacionadas a ele (o habitus) comunicam sua adequação às necessidades imanentes dos diversos campos da sociedade (como o da saúde, o da moda e o do esporte) e tratam de posicionar os indivíduos no espaço social. ${ }^{1-3}$

A cada dia que passa, a preocupação com o corpo tem maior incidência no modo de vida das pessoas. Essa preocupação se vislumbra claramente na mídia, entendida como um dos principais lugares de construção da realidade social, até porque a opinião pública tem se tornado cada vez mais dependente dessa máquina discursiva, campo cada vez mais autônomo dos restantes campos sociais como esfera obrigatória da visibilidade e da notoriedade. Desse modo, entende-se que o discurso da publicidade acompanhou e ditou as transformações de cada período histórico, mantendo e influenciando até hoje as pessoas. ${ }^{4,5}$

A imagem tem um papel fundamental na formação dos sentidos, pois ela e a palavra constroem juntas o sentido global da comunicação, muitas vezes implícito. Por isso, a necessidade de se desenvolver habilidades que vão além da decodificação do visual e que possibilitem a construção de significados a partir da leitura simultânea de palavras e imagens. ${ }^{6}$

O objetivo deste trabalho foi analisar anúncios de alimentos e bebidas que contêm a figura corporal feminina total ou fragmentada, veiculados nas revistas Seleções do Reader's Digest, no período de 1944-1948, e Claudia, no período de 2004-2008. O desenho do estudo foi direcionado pela análise semiótica dos anúncios de revistas, tendo a mulher como objeto principal de interesse, a fim de compreender o imaginário social da figura feminina em dois momentos de nossa história.

O anúncio é uma das principais formas de se vender produtos e serviços, apresentando suas qualidades e benefícios, uma mistura de imagens, símbolos, sentimentos e valores resultantes das necessidades da comensalidade. ${ }^{7}$ Visto que são poucos os estudos existentes sobre anúncios de alimentos e bebidas veiculados em revistas e sua grande importância em âmbito social, esta pesquisa se justifica pela contribuição para o entendimento do significado dos códigos estabelecidos no universo do discurso humano e permite compreender a produção da representação do corpo da mulher no imaginário social.

\section{Imaginário social}

Ao longo da História, todas as sociedades produziram suas próprias representações globais. Segundo Pesavento, trata-se de ideias-imagens mediante as quais elas se atribuem uma identidade, estabelecem suas divisões, legitimam seu poder e concebem modelos para a conduta de seus membros. Então, seriam representações coletivas da realidade, e não reflexos da mesma. ${ }^{8}$

Conhecer uma realidade significa percebê-la como historicamente determinada. Ela é constituída por sujeitos que a representam, a simbolizam. Sob a forma de percepção, de intuição, 
de sensações, de concepções, a realidade é sempre uma realidade para um indivíduo ou grupo de indivíduos que compartilham entre si o seu sentido. Além dos indivíduos serem cognoscentes, concretos, são também desejosos, imaginativos, sonhadores, capazes de fabular, de simbolizar o real existente e o real possível. Na realidade, a razão e a emoção estão imbricadas e não há como dicotomizá-las. Na unidade do ato perceptivo, pensa-se sentindo, sente-se pensando. Portanto, a existência resulta de um ato complexo em que confluem o sentir e o pensar, mas também o desejar, o sonhar. ${ }^{9}$

A imagem é a revelação de uma outra coisa que não ela própria. Pensar alegoricamente implica referir-se a uma coisa, mas apontar para uma outra, para um sentido mais além. Mais do que isso, implica realizar a representação concreta de uma ideia abstrata, cujo sentido não é manifesto. Subjacente ao que se vê, se lê ou se imagina, a alegoria comporta um outro conteúdo. ${ }^{8}$

A partir de uma estrutura de sentidos, constituída socialmente, a realidade se dá a conhecer sob formas discursivas, falas múltiplas: escrita, gestual, imagética, enfim, modos simbólicos de dizer o mundo. Logo, investigar uma realidade social pressupõe contar com um conjunto coordenado de representações, uma estrutura de sentidos, de significados que circulam entre seus membros, mediante diferentes formas de linguagem: esse conjunto é o imaginário social. ${ }^{9}$

Portanto, o domínio do imaginário é constituído pelo conjunto das representações que exorbitam do limite colocado pelas constatações da experiência e pelos encadeamentos dedutivos que estas autorizam. Assim, cada cultura, cada sociedade, e até mesmo cada nível de uma sociedade complexa, têm seu imaginário. ${ }^{10}$

\section{Publicidade: análise semiótica de imagens}

Os meios de comunicação são grandes máquinas de sedução que trabalham na instituição e modificação do imaginário social, pois mediante alegorias, metáforas, elucidações, as máquinas de sedução vão tocando todo tempo nosso campo simbólico, nossos ideais, nossos sagrados, nossas utopias. ${ }^{9}$ Pode-se considerar como função latente da mídia tudo o que ela procura vender que não seja concretamente o produto em si, mas sua magia, sua maneira de apresentar ideologicamente o sistema vigente, ideias, conceitos, valores, formas de relacionamento. ${ }^{11}$

As imagens estão presentes em nosso cotidiano desde cedo, de forma real ou imaginária. Podese entendê-las como representação mental, ilustração, aspecto construtivo e identitário, lembrança visual, metáfora, aparência, entre outros. O que há de comum em todas as definições é o fato de remeter à analogia, algo que se assemelha a outra coisa. Esse denominador comum da analogia, ou da semelhança, coloca de imediato a imagem na categoria das representações. ${ }^{12}$ 
Entre todas as teorias que podem abordar a imagem, o ponto de vista semiótico considera o modo de produção de sentido, a maneira como a mensagem provoca significações, verifica categorias de signos, se tem especificidade, leis próprias de organização, e procura significações particulares. $^{13}$

Na presente pesquisa, o recorte se baseia na análise da imagem do corpo feminino, num contexto da publicidade de alimentos e bebidas, onde a mensagem é conativa, e centrada na implicação do destinatário. Trata-se de um estudo descritivo, com abordagem qualitativa associada à quantitativa. Utilizou-se, para análise dos anúncios, a semiótica, seguindo o referencial teórico de Gemma Penn, e para a tabulação dos dados, a estatística descritiva simples. ${ }^{14}$

Foram selecionadas, aleatoriamente, quatro edições por ano da revista Seleções Reader's Digest, no período de 1944 a 1948, e quatro edições por ano da revista Claudia, no período de 2004 a 2008. Entre esses exemplares, foram estudados os anúncios de alimentos e bebidas (não alcoólicas) que contêm a figura corporal feminina total ou fragmentada.

Acreditamos na relevância da análise de Seleções por ser uma revista de muita influência no Brasil a partir da década de 1940, quando os valores do american way of life estavam em alta e ser "moderno" significava seguir esse modelo. Foi um período caracterizado por um boom no consumo e de grande expansão na área da publicidade. Outra questão que mostra a importância da revista para a apreensão do imaginário da época é a grande quantidade de anúncios que a revista possuía, dos mais diversos produtos, dirigido a todas as pessoas, e que serviu como um instrumento ideológico da presença americana. Vale ressaltar que a revista Seleções não tinha como objetivo um público-alvo específico, atingindo um público bastante heterogêneo e a diversas faixas etárias. Por isso, sempre foi uma revista de difícil classificação: educativa, variedades, família, etc. ${ }^{15}$

As revistas ilustradas são veículos de grande destaque no período, responsáveis por influenciar comportamentos e criar modismos. Através delas e dos "anúncios" que veiculavam é possível termos uma perspectiva da construção histórica dos significados culturais brasileiros em um período de transformações substanciais e de complexa negociação de nossa identidade cultural.?

Claudia é uma revista criada pelo Núcleo de Comportamento da Editora Abril, em outubro de 1961, destinada ao público feminino, que aborda o cotidiano, o comportamento e assuntos femininos através de discursos de diferentes significados e representações. É definida como a mais completa revista feminina, que está ao seu lado em todos os desafios e traz a maior variedade de assuntos relevantes em sua vida: família, amor, carreira, beleza, moda e qualidade de vida. ${ }^{16} \mathrm{Claudia}$ é uma revista comercial mensal brasileira, com circulação de 450 mil exemplares e 1,8 milhão de leitoras. ${ }^{17}$ A revista se firmou como uma das mais importantes para a mulher. ${ }^{18}$ 
A partir do passado, é possível estudar a contemporaneidade e os modos de consumo na sociedade. A revista feminina é um produto cultural que reflete cognições sobre os papéis sociais destinados à mulher, como mãe, esposa, dona de casa e profissional, através de informações sobre alimentação, nutrição, saúde, estética, entre outros..$^{19}$

A alimentação é uma área de domínio feminino e é a mulher a encarregada de decidir sobre o consumo final, organizar e realizar a prática alimentar da família, assumindo o papel de dona de casa. Entretanto, com a maior participação da mulher no mercado de trabalho, com a industrialização de produtos alimentícios e modernas técnicas de marketing, novas práticas alimentares foram adotadas, práticas essas que visam à simplificação do trabalho e economia do tempo aliadas a maior preocupação com a saúde e a qualidade de vida..$^{20,21}$

Nesse contexto, a mulher se torna o principal alvo dos publicitários, que buscam manipular a vontade e desejo de consumo e veicular um padrão de beleza cultural que garante identidade frente à mulher moderna. ${ }^{21,22}$

\section{Representação corporal: mulheres em revista}

A representação corporal da mulher no imaginário social foi organizada em categorias (imagem multifuncional e percepção corporal) e subcategorias. Essa determinação emergiu da verificação da proposta dos anúncios em estabelecer, construir e divulgar uma imagem multifuncional da mulher, expondo atributos comportamentais e de percepção do corpo. Portanto, a publicidade trata de enquadrar nos conteúdos dos anúncios um entendimento sobre o corpo da mulher, uma representação estudada no sentido de Erving Goffman. ${ }^{23-25}$ Para isso, compreende-se que a revista expõe nos seus anúncios uma mulher virtual, e que essa mulher, num ato comunicativo, representa um padrão de conduta com atributos socialmente adequados.

A maneira como o indivíduo lida, sente e percebe o seu corpo reflete uma realidade coletiva, consequentemente, o corpo, antes de tudo, passa a existir e ter um sentido dentro de um contexto social, que o constrói, sendo-lhe atribuídas representações constituídas de acepções, imagens e significados dentro de um universo simbólico, tornando-se um fato cultural.

A representação corporal da mulher no imaginário social foi organizada em categorias e subcategorias, com 88 e 167 unidades de registro nos anúncios da amostra das revistas Seleções, no período de 1944 a 1948, e Claudia, no período de 2004 a 2008, respectivamente. Os atributos do corpo feminino na construção social da identidade da mulher estão identificados na tabela 1.

Vale ressaltar que em um mesmo anúncio pode existir mais de uma imagem do papel funcional da mulher e mais de uma percepção do corpo feminino. 
Tabela 1. Atributos do corpo feminino no imaginário social presentes nos anúncios de alimentos e bebidas da amostra de revistas Seleções (1944-1948) e Claudia (2004-2008) e frequência de verificação das unidades de registro.

\begin{tabular}{l|l|c|c|c|c}
\hline \multirow{2}{*}{ Categorias } & Subcategorias & \multicolumn{2}{|c|}{ Seleções } & \multicolumn{2}{c}{ Claudia } \\
\hline \multirow{4}{*}{$\begin{array}{l}\text { Imagem } \\
\text { multifuncional }\end{array}$} & Mulher & 12 & 25,00 & 25 & 35,21 \\
\cline { 2 - 6 } & Mãe & 8 & 16,67 & 17 & 23,94 \\
\cline { 2 - 6 } & Esposa & 10 & 20,83 & 13 & 18,31 \\
\cline { 2 - 6 } & Dona de casa & 18 & 37,50 & 9 & 12,68 \\
\cline { 2 - 6 } & Profissional & 0 & 0 & 7 & 9,86 \\
\cline { 2 - 6 } & Total & 48 & 100 & 71 & 100 \\
\hline \multirow{4}{*}{$\begin{array}{l}\text { Percepção } \\
\text { corporal }\end{array}$} & Saúde/ equilibrado & 2 & 5,00 & 22 & 22,92 \\
\cline { 2 - 6 } & Amor/ sexualidade & 8 & 20,00 & 20 & 20,83 \\
\cline { 2 - 6 } & Beleza/ bonito & 5 & 12,50 & 21 & 21,87 \\
\cline { 2 - 6 } & Conhecimento/ inteligente & 7 & 17,50 & 3 & 3,13 \\
\cline { 2 - 6 } & Alegria/ feliz & 15 & 37,50 & 25 & 26,04 \\
\cline { 2 - 6 } & $\begin{array}{l}\text { Relacionamentos sociais/ } \\
\text { amigo }\end{array}$ & 3 & 7,50 & 5 & 5,21 \\
\cline { 2 - 6 } & Total & 40 & 100 & 96 & 100 \\
\hline
\end{tabular}

Goffman explica que nas interações sociais os indivíduos representam (no sentido de um teatro) o que gostariam de ser, utilizando-se de artimanhas (máscaras) para que as pessoas realmente acreditem que o que estão vendo é a imagem real, enquanto no seu íntimo o indivíduo sabe que está representando e que, de fato, essa é sua imagem virtual. ${ }^{24,25}$

Ainda segundo Goffman, isso ocorre de maneira inconsciente e diariamente os indivíduos se escondem atrás dessas máscaras, a fim de ocultar sua imagem real, de forma que os estigmas sejam abafados pela imagem virtual criada por cada um, em razão da necessidade social de pertencer a determinados grupos, precisando ser semelhante ou igual aos que os compõem. O modo como o indivíduo se sente configura a sua informação pessoal, a qual é transmitida por um símbolo que imprime posição de prestígio, popularmente chamado de "status". ${ }^{25}$ 
Esses símbolos foram aqui estudados e apresentados na forma de atributos do corpo feminino no imaginário social. Ao enquadrar uma imagem que se apresenta para que os outros a reconheçam foi possível verificar que os anúncios exploram a representação corporal de uma mulher que, além de cuidar de si mesma, está envolvida com outras atividades funcionais do cotidiano.

A categoria de imagem multifuncional, com 48 unidades de registro em Seleções e 71 unidades de registro em Claudia, apresenta um corpo voltado para si e para os outros, ou seja, em que a mulher estampada nos anúncios reclama, solicita um status de funcionalidade, cria uma imagem virtual que considera socialmente adequada (mulher em geral), pautada pelas preocupações com os filhos (no seu papel de mãe que entende e atende os filhos), com o marido (esposa/ companheira), trabalho (no seu papel de profissional inserida no mercado de trabalho) e com a própria casa (no seu papel de dona de casa que cozinha, limpa, lava, passa, cuida do espaço familiar).

Em relação a essa imagem de funcionalidade corporal da mulher, salienta-se a evidência do papel de dona de casa na amostra de anúncios de Seleções (37,50\%), publicados no período de 1944 a 1948, que não tem tanta expressividade na de anúncios de Claudia (12,68\%) veiculados no período de 2004 a 2008. Contudo, a função de trabalho desempenhada como profissional inserida no mercado se mostra bastante significativa no período recente $(9,86 \%)$ quando comparada à década de 1940, quando não possuía nenhuma expressão (0\%).

Além disso, a função mulher (35,21\%) e mãe (23,94\%) apresenta maior frequência nos anúncios de Claudia do que em Seleções (25\% e 16,67\%, respectivamente). Em compensação, a função de esposa é mais presente nos anúncios de Seleções, correspondendo a 20,83\%, enquanto em Claudia tal função aparece em 18,31\% dos anúncios analisados.

A percepção corporal, categoria com 40 unidades de registro em Seleções e 96 unidades de registro em Claudia, faz referência a uma imagem corporal autodirecionada, isto é, aquela em que a mulher também proclama e reclama uma representação de imagem virtual de autovalorização e autoestima socialmente adequada. Esta representação, de acordo com os resultados encontrados, conta com atributos como a saúde (de um corpo equilibrado), o amor (de um corpo com sexualidade), a beleza (de um corpo bonito), o conhecimento (de um corpo inteligente), a alegria (de um corpo feliz) e os relacionamentos sociais (de um corpo amigo).

Entre os atributos mais evidentes da percepção do corpo feminino presentes nos conteúdos dos anúncios da revista Seleções estão aqueles vinculados à alegria (37,50\%) e ao amor (20\%). A percepção corporal de um corpo inteligente e bonito aparece em terceiro e quarto lugar, respectivamente. Nos anúncios de Claudia, também ficou em primeiro lugar a de um corpo feliz (26,04\%), seguida pela subcategoria de um corpo equilibrado (22,92\%). A de um corpo voltado para saúde foi bem menos representativa em Seleções $(5,0 \%)$. Vale ressaltar que outros atributos, como um corpo 
bonito e um corpo com sexualidade, apresentaram valores muito próximos (21,87\% e 20,83\%, respectivamente) na amostra de Claudia. O corpo amigo é uma subcategoria da percepção corporal pouco frequente nas duas revistas.

Esses resultados apontam para o entendimento de que as pessoas que leem a revista devem realmente acreditar que o que estão vendo é a imagem corporal real de uma mulher que, por um lado, é evidentemente funcional, ocupando simultaneamente vários papéis sociais e, por outro, ainda que com menos evidência, uma mulher com autoestima e autoconhecimento. Estes signos alimentam o relacionamento, a interação social.

O anúncio das Sopas Jurema (Figura 1), publicado na revista Claudia, em julho de 2008, apresenta múltiplos papéis femininos em que cada figura feminina desempenha uma função e sugere uma percepção de seu corpo. Assim, a partir desse anúncio, podemos sugerir que estão destacadas as cinco subcategorias da imagem multifuncional, pois está caracterizada a imagem de mulher em geral (figura feminina de pele branca, loira, com roupa de ginástica, que está se exercitando com alteres); de mãe (figura feminina de pele branca, grávida, que segura uma criança pela mão e prepara comida); esposa/ companheira (figura feminina de pele branca beijando um homem); dona de casa (figura feminina de pele branca, no centro da imagem, que aparece de olhos fechados ao lado de uma concha, como se estivesse apreciando o aroma da preparação); e profissional (figura feminina de pele morena, bem vestida, que faz a refeição sozinha, sentada à mesa). Além disso, também é transmitida a ideia de um corpo bonito, saudável, sexualizado, feliz e inteligente, respectivamente. 


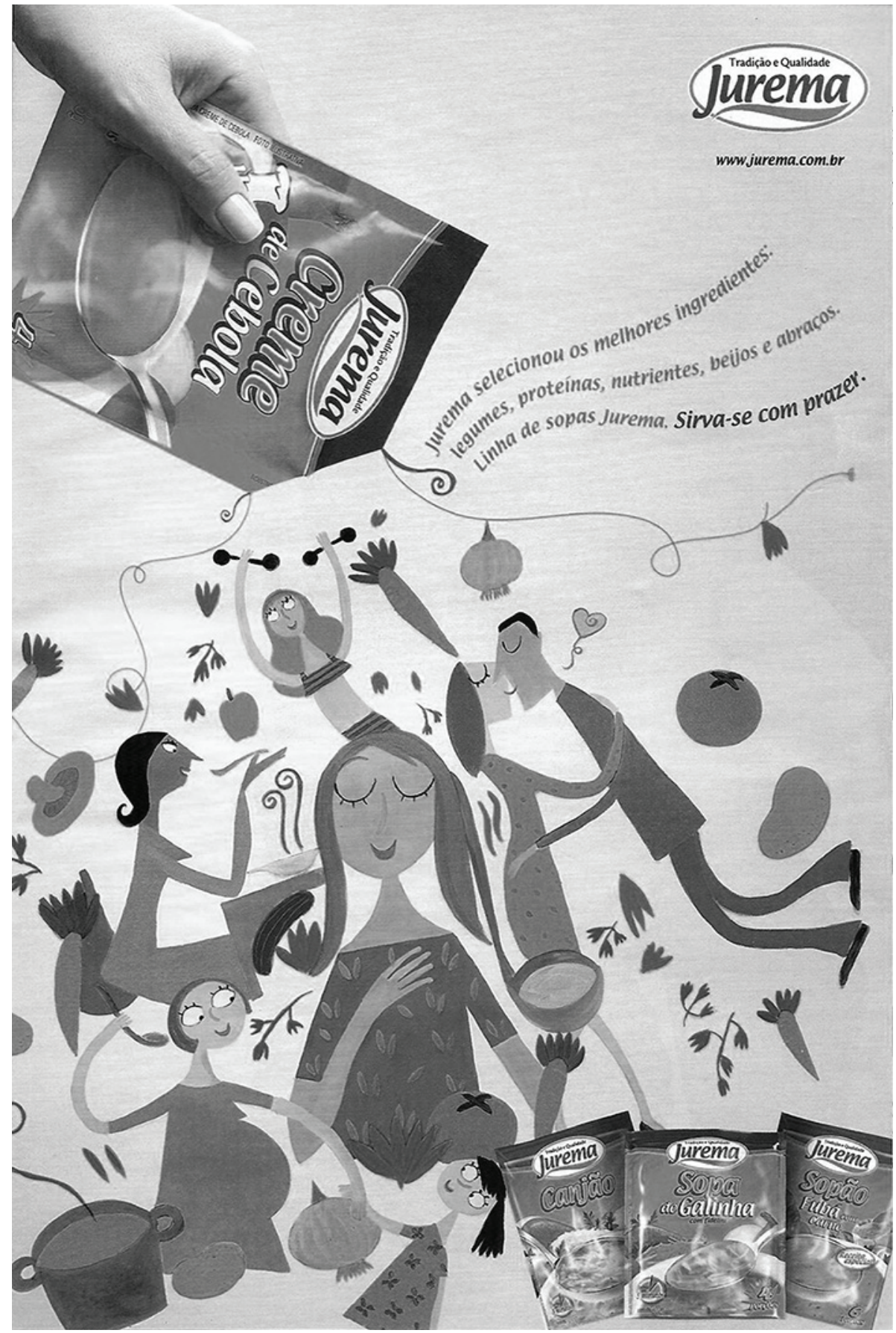

Figura 1. Anúncio Sopas Jurema, Revista Claudia, julho de 2008. 
Os anúncios de Seleções não apresentam nenhuma figura feminina de raça negra e apenas uma oriental. Apesar de seis décadas depois, a amostra dos anúncios de Claudia também possui baixíssima representatividade de mulheres de outras raças ou cor de pele que não seja a branca, pois inclui apenas uma mulher de raça negra e nenhuma oriental. Talvez este fato esteja relacionado ao público-alvo das revistas, logo, entende-se que é o público que vai consumir os produtos anunciados, estando tal fato provavelmente associado à condição financeira das mulheres.

Somente 18,18\% da amostra de anúncios de Seleções, de 1944 a 1948, utilizam o corpo feminino por inteiro, enquanto em Claudia, de 2004 a 2008, 42,86\%, e quando se utiliza de uma parte do corpo, ela não está mais flutuando nos dias de hoje, como acontece em alguns anúncios da década de 1940, mas representa um enquadramento fotográfico da câmera em que se percebe que aquela parte pertence a um todo.

$\mathrm{Na}$ amostra de anúncios de alimentos e bebidas das revistas Seleções, observou-se que, entre os cinco anúncios em que a mulher está de corpo inteiro, em quatro as pernas aparecem de fora. No entreguerra (1918-1938), a burguesia representa uma época de liberação do corpo. Quando é travada uma outra relação entre o físico e as roupas, dá-se início a sua exposição. Não há mais lugar para roupas que o escondam, a mudança é ainda mais visível em relação ao vestuário feminino. Saem as cintas e corpetes, entram em cena as calcinhas e sutiãs. As roupas se encurtam e as pernas são valorizadas pelas meias. ${ }^{26}$

Já na década do ano 2000, o acessório feminino que mais chama a atenção é o biquíni, que aparece em 12,25\% dos anúncios da amostra da revista Claudia. A atual preocupação com a forma e o volume dos corpos está relacionada à importância que a dimensão estética e a questão da imagem ocupam, isso se reflete também nos impressionantes números da indústria de cosméticos e cirurgias plásticas. $\mathrm{O}$ ideal de corpo perfeito preconizado pela sociedade e veiculado pela mídia leva as mulheres, sobretudo na adolescência, a uma insatisfação crônica com seus corpos, adotando dietas altamente restritivas e exercícios físicos extenuantes como forma de compensar as calorias ingeridas a mais, na tentativa de corresponder ao modelo cultural vigente. Muitas delas buscam a recontextualização de seus corpos e isso, às vezes, é incentivado por algumas campanhas publicitárias de alimentos e bebidas, como se o corpo estivesse sempre a ser redefinido, a ganhar uma atualização de acordo com o padrão da sociedade.

No que se refere às mulheres, particularmente, para além dos papéis de profissional, mãe e esposa, elas devem estar bem cuidadas e em forma, de modo que tais papéis sejam mais valorizados socialmente. ${ }^{27} \mathrm{O}$ corpo deve ser gerenciado de maneira a estar sempre belo, competitivo, tanto no mercado de trabalho quanto para a sedução. ${ }^{28}$ Reeducação alimentar, atividade física, tratamento de prevenção são expressões que predominam no imaginário feminino, assim como "ser feliz a qualquer preço", "linda, leve e realizada", "você é responsável por seu corpo" são algumas mensagens publicitárias que legitimam a mulher brasileira hoje em dia. ${ }^{29,30}$ 


\section{Considerações finais}

Os dados apresentados e discutidos permitiram compreender que a produção da representação do corpo da mulher pela publicidade foi desenvolvida a fim de operar esforços para enquadrar (no sentido de estabelecer, construir, proclamar) uma determinada imagem do corpo feminino no imaginário social. Nessa tarefa, os esquemas geradores da percepção, avaliação e seleção dos conteúdos parecem estar restritos à dimensão multifuncional na sociedade (mulher, mãe, esposa, dona de casa e profissional) e pela sua dimensão de percepção corporal (que tem saúde, beleza, alegria, inteligência, sexualidade).

No imaginário da revista Seleções transitam dois tipos de mulher claramente delineados. A "mulher tradicional" (mãe-esposa-dona de casa), sem muitas vaidades, totalmente voltada para a família e que é protagonista dos anúncios de alimentos. E a "mulher moderna”, que, além de mãeesposa-dona de casa, ainda é vaidosa, bonita, sensual e geralmente é protagonista de anúncios de bebidas (refrigerante Coca-Cola). Essas “duas mulheres”, sob um olhar desinteressado, poderiam parecer opostas e sem qualquer relação entre si, em uma tentativa de seguir a ideia de neutralidade proposta por Seleções. Porém, esta revista apresenta dois tipos muito próximos de mulheres, que representam apenas um modelo de mulher tradicional: a "rainha do lar". Os anúncios falam claramente de relacionamentos, filhos e de como agradar ao marido através da comida. Assim, percebe-se uma manutenção dos valores tradicionais e conservadores do papel feminino.

Já na revista Claudia, os mesmos papéis são executados pela mulher. Entretanto, constatamos um "avanço" no seu perfil ao longo das décadas: uma mulher que aparece inserida no mercado de trabalho (profissional), mais independente, ativa, sensual, vaidosa e feliz. Além disso, observou-se um aumento significativo das associações entre o consumo do alimento ou bebida com a mudança da forma corporal e melhora da performance física. Esse fato demonstra o quanto a sociedade expõe e/ou impõe um padrão de estética e beleza a ser alcançado pelas mulheres, a partir da mensagem publicitária de que ela é capaz de modelar o seu corpo como uma matéria-prima, ainda inacabada.

Observou-se também um aumento da imagem de mãe nos anúncios de Cláudia, retratando a influência da mulher no consumo infantil, sendo grande alvo das campanhas publicitárias. O mais incrível de tudo isso é que já se passaram 60 anos e o pensamento em relação às mulheres quanto aos ideais de comportamento e papéis sociais pode ter se modificado, mas, no cotidiano, são poucas as mudanças, sobretudo no que tange à divisão das tarefas domésticas. Essas tarefas são historicamente consideradas femininas, pois cozinhar e cuidar dos filhos continuam sendo atividades amplamente executadas por mulheres e de sua responsabilidade.

Assim, podemos chamar a mulher dos dias atuais de "mulher hipermoderna", fazendo referência ao conceito de hipermodernidade de Gilles Lipovetsky. ${ }^{30}$ Além de exercer todos os papéis sociais (mãe-esposa-dona de casa-mulher-profissional), passou a um estágio superior de modernização 
à medida que desempenha mais funções na sociedade. Desse modo, entende-se que não houve uma ruptura por completo em relação aos modelos femininos da década de 1940, porém uma potencialização das tarefas e dos modos de ser, em que a mulher contemporânea é hipervaidosa, hiperbonita e hipersensual!

A publicidade opera como uma bússola para a navegação social, um dispositivo capaz de guardar uma impressionante memória coletiva que nos permite interpretar o imaginário cultural no qual vivemos e as práticas que, através dele, experimentamos. ${ }^{7}$ Portanto, a análise dos anúncios nos mostrou que a publicidade funciona como uma grande reserva cultural de signos e que nos serve como referencial para entender a evolução de comportamento em uma sociedade em um dado momento histórico. O trabalho nos permitiu concluir que houve uma mudança no perfil da mulher em termos de conteúdo e visibilidade, principalmente a partir da maior exposição do corpo nos anúncios publicitários.

\section{Referências}

1. Bourdieu P. O poder simbólico. 2. ed. Rio de Janeiro: Bertrand Brasil; 1998.

2. Bourdieu P. Meditações pascalianas. Rio de Janeiro: Bertrand Brasil; 2001.

3. Bourdieu P. Razões práticas: sobre a teoria da ação. 5. ed. Campinas, SP: Papirus; 2004.

4. Esteves JP. A ética da comunicação e os media modernos. Lisboa: Fundação Calouste Gulbenkian; 1998.

5. Rodrigues AD. Estratégias da comunicação. 2. ed. Lisboa: Editorial Presença; 1997.

6. Silva GFP. A mensagem visual nos anúncios publicitários. Caderno de Letras da UFF 2012; 44:329-346.

7. Aucar B, Rocha E, Pereira C. Os anúncios nas revistas ilustradas: imaginário e valores brasileiros no início do século XX. In: Moraes ALC, Lisboa Filho FF, Pavan MA, organizadores. Histórias e reflexões da publicidade e propaganda e da comunicação institucional: Rede Alcar - História da Mídia. Natal, RN: EDUFRN, 2015. p. 21-52.

8. Pesavento SJ. 500 anos de América: imaginário e utopia. Porto Alegre: Ed. Universidade, UFRGS; 1992.

9. Teves N. Imaginário social e educação. Rio de Janeiro: Gryphus; 1992.

10. Le Goof J. organizador. A história nova. 2. ed. São Paulo: Martins Fontes; 1993.

11. Rocha E. A sociedade do sonho: comunicação, cultura e consumo. 4. ed. Rio de Janeiro: Mauad; 1995.

12. Joly M. Introdução à análise da imagem. Lisboa: Ed. 70; 1994.

13. Joly M. A imagem e a sua interpretação. Lisboa: Ed. 70; 2003.

14. Bauer MW, Gaskell G. Pesquisa qualitativa com texto: imagem e som: um manual prático. Petrópolis: Vozes; 2002. 
15. Topke DR. Miss anos dourados: as representações da mulher nos anúncios de Seleções do Reader’s Digest [dissertação]. [Rio de Janeiro]: Instituto de Psicologia, Programa de Mestrado em Psicologia Social, Universidade do Estado do Rio de Janeiro; 2007.

16. Revista Claudia. Rio de Janeiro: Abril; 1989-

17. Meio \& Mensagem [Internet]. Revista Claudia celebra 50 anos. [acesso em: 25 set. 2012]. Disponível em: http://www.meioemensagem.com.br/home/midia/2011/09/27/revista-claudia-celebra-50-anos.html

18. Instituto Verificador de Circulação. Posição participação e evolução das publicações. [acesso em: 29 out. 2007]. Disponível em: http://www.professorloureiro.com.br/imagens/ivc-jornal-dias-uteissetembro-2007.pdf

19. Duarte ARF. A grande dama do feminismo no Brasil. Estudos Feministas 2006; 14(2):549-71.

20. Chaud DMA, Marchioni DML. Nutrição e mídia: uma combinação às vezes indigesta. Revista Higiene Alimentar 2004; 18(116/117):18-22.

21. Canesqui AM. Comentários sobre os estudos antropológicos da alimentação. In: Canesqui AM, Garcia RWD. Antropologia e nutrição: um diálogo possível. Rio de Janeiro: Fiocruz; 2005. p. 23-5. Coleção Antropologia e Saúde

22. Andrade A, Bosi MLM. Mídia e subjetividade: impacto no comportamento alimentar feminino. Revista de Nutrição 2003; 16(1):117-25.

23. Goffman E. El Ritual de la interacción. Buenos Aires: Tiempo Contemporaneo; 1971.

24. Goffman E. A representação do eu na vida cotidiana. Petrópolis: Vozes; 1975.

25. Goffman E. Estigma: notas sobre a manipulação da identidade deteriorada. 4. ed. Rio de Janeiro: Guanabara Koogan; 1988.

26. Vasconcelos N, Sudo I, Sudo N. Um peso na alma. Revista Mal-estar e Subjetividade 2004; 4(1):65-93.

27. Montefusco EVR. Jovem para sempre! Publicidade em revistas femininas e suas promessas de administração do tempo. Revista Psicologia e Saúde 2015; 7(1):18-29.

28. Baudrillard J. A Sociedade de consumo. Lisboa: Arte e Comunicação; 2008.

29. Felerico S. Identidade mulher: práticas de consumo e a percepção da comunicação estética na maturidade. In: Moraes ALC, Lisboa Filho FF, Pavan MA, organizadores. Histórias e reflexões da publicidade e propaganda e da comunicação institucional: Rede Alcar - história da mídia. Natal, RN: EDUFRN; 2015. p. 277-98.

30. Lipovetsky G. Os tempos hipermodernos. São Paulo: Barcarolla; 2004. 129 p.

Recebido: $14 / 1 / 2016$

Revisado: $19 / 8 / 2016$

Aceito: 26/10/2016 